\title{
Differentiation of Campylobacter species by AFLP fingerprinting
}

\author{
Birgitta Duim, ${ }^{1}$ Peter A. R. Vandamme, ${ }^{2}$ Alan Rigter, ${ }^{1}$ Severine Laevens, ${ }^{2}$ \\ Jeroen R. Dijkstra and Jaap A. Wagenaar ${ }^{1}$
}

\footnotetext{
1 Institute for Animal Science and Health (ID-Lelystad), PO Box 65, 8200 AB Lelystad, The Netherlands

2 Laboratorium voor Microbiologie, University of Gent, Gent, Belgium
}

Author for correspondence: Birgitta Duim. Tel: +31320 238157. Fax: +31 320238153. e-mail: b.duim@id.wag-ur.nl

The fluorescent amplified fragment length polymorphism (AFLP) fingerprinting method was tested for its ability to identify and subtype the most important Campylobacter species found in veterinary infections. Sixty-nine reference strains and 19 clinical isolates of Campylobacter jejuni subsp. jejuni, Campylobacter jejuni subsp. doylei, Campylobacter upsaliensis, Campylobacter coli, Campylobacter lari, Campylobacter fetus subsp. fetus, C. fetus subsp. venerealis, Campylobacter hyointestinalis subsp. hyointestinalis, C. hyointestinalis subsp. lawsonii, Campylobacter mucosalis, Campylobacter helveticus and Campylobacter sputorum were subjected to analysis. The topology of the dendrogram obtained by numerical analysis of the AFLP profiles did not reflect the phylogenetic relationships as derived from $16 \mathrm{~S}$ rDNA sequence comparison. However, except for C. lari, AFLP analysis grouped the strains that belonged to the same genomic species into distinct clusters. $C$. lari strains were separated into two distinct AFLP groups, which corresponded with nalidixic-acid-sensitive and -resistant variants of $C$. lari. These results correlated with data from whole-cell protein profiling. Within $C$. jejuni, $C$. hyointestinalis and $C$. fetus, strains could be identified at the subspecies level. AFLP analysis also allowed the subtyping of most species at the strain level. It is concluded that AFLP analysis is a valuable tool for concurrent identification of campylobacters at the species, subspecies and strain levels. In addition, the data confirm and extend previous reports showing that $C$. lari is a heterogeneous species that may comprise multiple taxa.

Keywords: taxonomy, typing, epidemiology, veterinary infections

\section{INTRODUCTION}

Campylobacter species have been recognized as important pathogens in humans and animals. Within the genus Campylobacter, the thermotolerant species Campylobacter jejuni and Campylobacter coli cause gastroenteritis in humans, and colonize poultry, pigs and cattle. C. jejuni is considered to be the most common cause of sporadic bacterial enteritis worldwide (Skirrow \& Blaser, 1992). Other Campylobacter species can be considered as primary human pathogens, e.g. Campylobacter upsaliensis, Campylobacter lari, Campylobacter fetus subsp. fetus and C. jejuni subsp. doyle $i$; because of inappropriate isolation and identi-

Abbreviations: AFLP, amplified fragment length polymorphism; UPGMA, unweighted pair-group method using arithmetic averages. fication methods, they are thought to be significantly underdiagnosed causes of gastrointestinal diseases (Lastovica \& Skirrow, 2000).

Several Campylobacter species are associated with infections in animals. C. upsaliensis strains have been isolated from healthy and diarrhoeic dogs and cats (Bourke et al., 1998). The subspecies C. fetus subsp. venerealis causes abortion and infertility in cattle, whereas C. fetus subsp. fetus is an important cause of sporadic abortion in sheep and cattle (Garcia et al., 1983; Lastovica \& Skirrow, 2000). Campylobacter byointestinalis and Campylobacter mucosalis have been isolated from pigs with proliferative enteritis and other enteric diseases. The species C. hyointestinalis is divided into two subpecies, namely C. hyointestinalis subsp. byointestinalis and C. hyointestinalis subsp. lawsonii (On et al., 1995). The latter has been isolated from pig 
Table 1. Campylobacter strains used for AFLP analysis

\begin{tabular}{|c|c|c|}
\hline Species and strain code* & Source & $\begin{array}{l}\text { Country and } \\
\text { isolation year }\end{array}$ \\
\hline \multicolumn{3}{|l|}{ C. jejuni subsp. jejuni } \\
\hline LMG 9081 & Human faeces & South America, 1979 \\
\hline LMG 9221 & Child faeces & Belgium \\
\hline LMG 14244 & Human faeces & The Netherlands \\
\hline LMG 14317 & Human faeces & The Netherlands \\
\hline LMG 15906 & Human faeces & Brazil \\
\hline LMG 15907 & Human faeces & Brazil \\
\hline ATCC 29428 & Child, diarrhoea & - \\
\hline $\mathrm{R}-2631$ & Human faeces & Belgium \\
\hline C356† & Chicken faeces & The Netherlands, 1990 \\
\hline $\mathrm{C} 2555+$ & Chicken faeces & The Netherlands, 1992 \\
\hline C2412† & Chicken faeces & The Netherlands, 1992 \\
\hline C2651† & Chicken faeces & The Netherlands, 1993 \\
\hline C2345† & Chicken faeces & The Netherlands, 1992 \\
\hline C2143† & Chicken faeces & The Netherlands, 1992 \\
\hline $\mathrm{C} 2172 \dagger$ & Human, diarrhoea & The Netherlands, 1993 \\
\hline \multicolumn{3}{|l|}{ C. jejuni subsp. doylei } \\
\hline LMG 8556 & Human stomach & UK, 1992 \\
\hline LMG 9243 & Child, faeces & Belgium, 1986 \\
\hline LMG 8843 & Child, diarrhoea & Australia, 1982-1983 \\
\hline LMG 8870 & Child, blood & South Africa, 1986 \\
\hline LMG 9255 & Child, faeces & Belgium, 1986 \\
\hline \multicolumn{3}{|l|}{ C. coli } \\
\hline LMG 15909 & Human faeces & Brazil \\
\hline LMG 15908 & Human faeces & Brazil \\
\hline LMG 15882 & Pig, enteritis & Australia, 1988 \\
\hline LMG 15884 & Pig, enteritis & Australia, 1991 \\
\hline LMG 15904 & Human faeces & Brazil \\
\hline LMG 15905 & Human faeces & Brazil \\
\hline ATCC 33559 & Pig faeces & Sweden \\
\hline $\mathrm{R}-2153$ & Human faeces & Belgium \\
\hline C2436† & Chicken faeces & The Netherlands, 1992 \\
\hline C2470† & Chicken faeces & The Netherlands, 1993 \\
\hline C2375† & Chicken faeces & The Netherlands, 1992 \\
\hline C2498† & Chicken faeces & The Netherlands, 1992 \\
\hline $\mathrm{C} 2155+$ & Chicken faeces & The Netherlands, 1993 \\
\hline \multicolumn{3}{|l|}{ C. upsaliensis } \\
\hline LMG 9124 & Child, faeces & Belgium, 1987 \\
\hline LMG 9129 & Child, diarrhoea & Belgium, 1986 \\
\hline LMG 8850 & Canine faeces & Sweden, 1980 \\
\hline LMG 8854 & Child, blood & South Africa, 1985-1988 \\
\hline LMG 9139 & Child, diarrhoea & Belgium, 1986 \\
\hline LMG 13480 & Child, faeces & Belgium \\
\hline LMG 10783 & Human faeces & Belgium \\
\hline $\mathrm{R}-2343$ & Human faeces & Belgium \\
\hline \multicolumn{3}{|l|}{ C. lari } \\
\hline LMG 9889 & Human & Canada \\
\hline LMG 7929 & Dog faeces & UK \\
\hline LMG 9913 & Human & - \\
\hline LMG 8845 & Child, faeces & - \\
\hline LMG 9152 & Horse intestine & Sweden, 1981 \\
\hline LMG 8846 & Herring gull, cloacae & Canada \\
\hline
\end{tabular}


Table 1 (cont.)

\begin{tabular}{|c|c|c|}
\hline Species and strain code* & Source & $\begin{array}{l}\text { Country and } \\
\text { isolation year }\end{array}$ \\
\hline LMG 9914 & Human & Canada \\
\hline LMG 11760 & Human & Canada, 1990 \\
\hline LMG 8844 & Seawater & UK, 1982-1983 \\
\hline $\mathrm{R}-1189$ & Human faeces & Belgium \\
\hline ATCC 35221 & Herring gull, cloacae & - \\
\hline \multicolumn{3}{|l|}{ C. hyointestinalis subsp. hyointestinalis } \\
\hline LMG 8214 & Pig intestine & France \\
\hline LMG 9276 & Child, diarrhoea & Belgium, 1986 \\
\hline LMG 7817 & Pig intestine & USA, 1980 \\
\hline LMG 8464 & Pig & - \\
\hline LMG 8540 & Beef calf, diarrhoea & USA, 1982 \\
\hline CCUG 14170 & Pig intestine & USA, 1983 \\
\hline \multicolumn{3}{|l|}{ C. hyointestinalis subsp. lawsonii } \\
\hline LMG 15912 & Human & Brazil \\
\hline LMG 14432 & Pig stomach & UK \\
\hline LMG 14433 & Pig stomach & UK \\
\hline LMG 14434 & Pig stomach & UK \\
\hline LMG 14435 & Pig stomach & UK \\
\hline \multicolumn{3}{|l|}{ C. helveticus } \\
\hline CCUG 30563 & Cat faeces & Switzerland, 1991 \\
\hline CCUG 30564 & Cat faeces & Switzerland, 1991 \\
\hline CCUG 34016 & Cat faeces & Sweden, 1995 \\
\hline CCUG 34042 & Cat faeces & Sweden, 1995 \\
\hline LMG 12639 & Cat, faeces & Switzerland, 1992 \\
\hline \multicolumn{3}{|l|}{ C. fetus subsp. fetus } \\
\hline LMG 9150 & Dog faeces & 1980 \\
\hline LMG 14744 & Human blood & Belgium \\
\hline LMG 12689 & Human blood & - \\
\hline LMG 8620 & Pig intestine & France \\
\hline $\mathrm{R}-4117$ & - & Finland \\
\hline ATCC 27374 & Sheep fetus, brain & - \\
\hline \multicolumn{3}{|l|}{ C. fetus subsp. venerealis } \\
\hline ATCC 19438 & Heifer, vaginal mucus & - \\
\hline LMG 6443 & Heifer, vaginal mucus & UK \\
\hline $5521 \neq$ & - & The Netherlands, 1993 \\
\hline $5522 \ddagger$ & - & The Netherlands, 1993 \\
\hline \multicolumn{3}{|l|}{ C. mucosalis } \\
\hline LMG 8266 & Pig intestine & UK, 1972 \\
\hline LMG 7794 & Pig intestine & UK, 1982 \\
\hline LMG 8433 & Pig intestine & - \\
\hline LMG 6265 & Pig intestine & UK, 1973 \\
\hline LMG 6448 & Pig & UK, 1972 \\
\hline C. sputorum bv. paraurelyticus LMG 11764 & Human stool & Canada, 1991 \\
\hline C. sputorum LMG 14261 & Human pus & Spain, 1993 \\
\hline C. sputorum bv. fecalis LMG 6617 & Ovine faeces & Canada \\
\hline C. sputorum bv. sputorum LMG 7795 & - & - \\
\hline C. sputorum bv. sputorum LMG 7975 & Pig intestine & UK \\
\hline
\end{tabular}

*Strain abbreviations: LMG, BCCM/LMG Bacteria Collection, Laboratorium voor Microbiologie, University of Gent, Gent, Belgium; ATCC, American Type Culture Collection, Manassas, VA, USA; CCUG, Culture Collection of the University of Göteborg, Göteborg, Sweden.

† Strains obtained from chickens during a study among randomly located farms in The Netherlands (Jacobs-Reitsma et al., 1994). $\ddagger$ Strains obtained from the Animal Health Service, Boxtel, The Netherlands. 
stomachs, but its role remains unknown (Gebhart et al., 1985). The pathogenicity of the species C. lari, isolated from the intestines of gulls, shellfish, fish and other animals, and the species Campylobacter helveticus, isolated from the faeces of domestic cats and dogs, is unknown (Endtz et al., 1997; Stanley et al., 1992). The species Campylobacter sputorum is considered to be a commensal of the animals in which it can be found. It has been isolated from the genital tracts and the faeces of bulls, and has been associated with several diseases in humans (Borczyk et al., 1988).

The classification of the genus Campylobacter has been significantly changed during the last decade. On the basis of phylogenetic results derived from DNA-rRNA hybridization and data from genotypic and phenotypic analyses of strains, the genus Campylobacter currently consists of 16 validly described Campylobacter species (Lawson et al., 2001; Logan et al., 2000; Vandamme et al., 1991). Appropriate identification of Campylobacter species is often hampered by a lack of biochemical differences and also by unreliable test reactions (Goossens \& Butzler, 1992; On, 1996). To study the prevalence of Campylobacter species in animal diseases, the natural distribution of species, and the incidence of these species in human infections, a method is needed that can concurrently identify Campylobacter strains to the species and strain levels. Amplified fragment length polymorphism analysis (AFLP), a random wholegenome fingerprinting method, has been used for highresolution typing of several bacteria in both epidemiological and taxonomic studies (Savelkoul et al., 1999). Recently, this method has been adapted for epidemiological typing of C. jejuni and C. coli. These studies demonstrated the subtyping of individual strains, and have already differentiated between two species (Duim et al., 1999, 2000; Kokotovic \& On, 1999; On \& Harrington, 2000). In this study, the value of AFLP analysis was determined for the identification and differentiation, at strain level, of nine Campylobacter species and three subspecies belonging to well-defined taxa and representing Campylobacter species that are very important in a veterinary context.

\section{METHODS}

Bacterial strains and culture conditions. A total of 88 strains were analysed. Fifty-nine reference strains of Campylobacter species were obtained from the BCCM/LMG (the Bacteria Collection, Laboratorium voor Microbiologie, University of Gent, Gent, Belgium). These strains consisted of six C. jejuni subsp. jejuni strains, five C. jejuni subsp. doylei strains, six C. coli strains, seven C. upsaliensis strains, nine C. lari strains, five C. hyointestinalis subsp. hyointestinalis strains, five $C$. byointestinalis subsp. lawsonii strains, four C. fetus subsp. fetus strains, one C. fetus subsp. venerealis strain, five $C$. mucosalis strains, one C. helveticus strain and five $C$. sputorum strains. Five reference strains (C. jejuni subsp. jejuni, C. coli, C. lari, C. fetus subsp. fetus and C. fetus subsp. venerealis) were obtained from the American Type Culture Collection (ATCC). Four C. helveticus strains and one $C$. byointestinalis subsp. hyointestinalis strain were obtained from the CCUG (the Culture Collection of the University of
Göteborg, Göteborg, Sweden). Also included were seven recent isolates - one C. jejuni strain, one C. coli strain, one $C$. upsaliensis strain and one C. lari strain (University of Gent, Belgium), as well as one C. fetus subsp. fetus strain and two C. fetus subsp. venerealis strains (Animal Health Service, Boxtel, The Netherlands), all of which were identified by whole-cell protein profiling ( $\mathrm{P}$. Vandamme, unpublished results) - and 12 field isolates of C. jejuni $(n=7)$ and C. coli $(n=5)$ (JacobsReitsma et al., 1994). Strain numbers and available information are listed in Table 1. Bacteria were grown on bloodagar plates supplemented with $5 \%(\mathrm{v} / \mathrm{v})$ sheep blood, at $37^{\circ} \mathrm{C}$ for 2-3 d, under microaerophilic conditions. An anoxomat system (Mart) was used to produce the following final gas mixture: $6 \% \mathrm{O}_{2}, 7 \% \mathrm{CO}_{2}, 80 \% \mathrm{~N}_{2}, 7 \% \mathrm{H}_{2}$ (by vol.). Bacterial cultures were stored at $-80{ }^{\circ} \mathrm{C}$ in $15 \%(\mathrm{w} / \mathrm{v})$ glycerol in heart infusion broth.

AFLP analysis. For the isolation of chromosomal DNA, freshly grown cells were scraped from plates and washed with $1 \mathrm{ml}$ TE (10 mM Tris/HCl, pH 8.0, $1 \mathrm{mM}$ EDTA). DNA was isolated using the PUREGENE kit (Gentra Systems). DNA integrity was checked by agarose gel electrophoresis, and DNA preparations were stored at $-20^{\circ} \mathrm{C}$. DNA concentrations were determined with a spectrophotometer and were standardized at $0 \cdot 1 \mu \mathrm{g} \mu \mathrm{l}^{-1}$.

AFLP analysis was performed according to the recently described AFLP method for Campylobacter genotyping, an adapted protocol of the AFLP Microbial Fingerprinting method of PE Applied Biosystems (Duim et al., 1999). In short, chromosomal DNA was digested with HindIII and HhaI, and, in a simultaneous reaction, the fragments were ligated to restriction-site-specific adapters for $2 \mathrm{~h}$ at $37^{\circ} \mathrm{C}$. Then a preselective PCR using the adapter-specific primers HindIII (5'-GACTGCGTACCAGCTT-3') and HhaI (5'-GATGAGTCCTGATCGC-3') was performed. Next, an aliquot was subjected to a selective PCR in which both primers contained an additional A nucleotide at the $3^{\prime}$-end: HindIII primer 5'-GACTGCGTACCAGCTTA-3' and HhaI primer 5'- GATGAGTCCTGATCGCA-3'. The 5' end of the HindIII primer contained a fluorescent label. The final products were run on a $7 \cdot 3 \%$ denaturing acrylamide sequencing gel for $5 \mathrm{~h}$, using an ABI 373A automated DNA sequencer.

Data processing. After electrophoresis, the data for the fluorescently labelled banding patterns were collected by using ABI GENESCAN software (PE Applied Biosystems). Each gel track, ranging from the size-marker $100 \mathrm{bp}$ band to the $500 \mathrm{bp}$ band, was imported in the software package GelCompar 4.1 (Applied Maths) with the program ABICON (Applied Maths). Patterns were normalized by reference to the molecular mass of the internal ROX-labelled size standard that was included in each sample. After normalization, the levels of genetic similarity between the AFLP patterns were calculated with the Pearson product-moment correlation coefficient $(r)$. For cluster analysis of AFLP banding patterns, the unweighted pair group method using arithmetic averages (UPGMA) was used (Vauterin \& Vauterin, 1992).

\section{RESULTS}

The AFLP conditions that were initially developed for analysis of C. jejuni and C. coli were used to analyse 88 strains that belonged to different Campylobacter species (Duim et al., 1999). The banding patterns of strains varied in terms of the distribution of bands ranging from 100 to 500 bp in size. Without adaptation of the method, banding patterns were obtained from all strains (Fig. 1). 


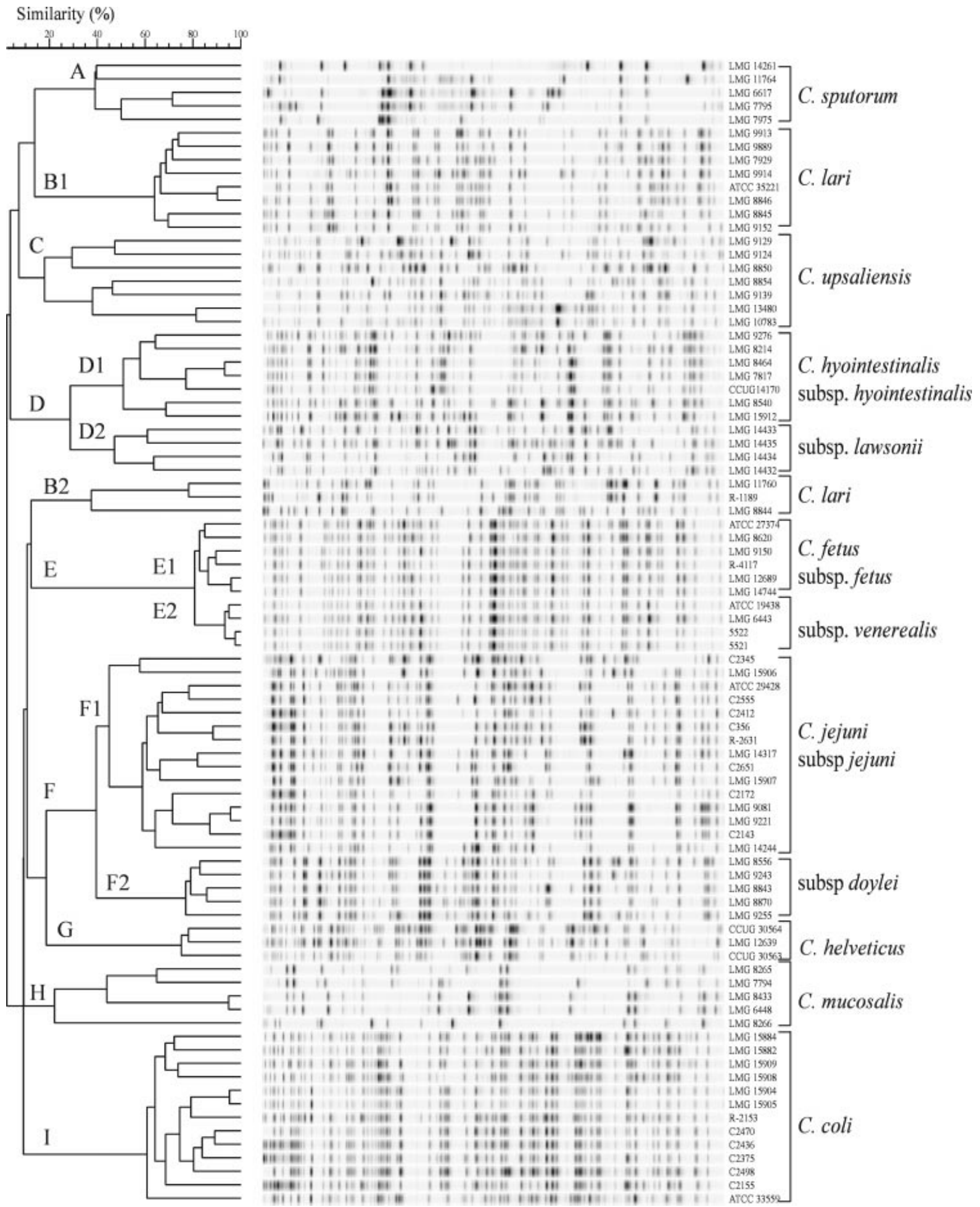

Fig. 1. Dendrogram of AFLP fingerprints of Campylobacter species and subspecies. The distinct AFLP clusters are indicated by letters and bars, which correspond to the indicated species names. The percentage genetic similarity between banding patterns is indicated.

\section{Reproducibility of the AFLP profiles}

The reproducibility of the AFLP profiles was defined as a $>90 \%$ similarity level between duplicated samples.
This was the mean similarity obtained between four independently obtained profiles for all 88 strains (i.e. four new DNA samples run on different gels) except for one strain of C. upsaliensis (R-2342) and two strains of 
C. helveticus (CCUG 34242 and CCUG 34016). The repeated samples of these strains showed only $60-80 \%$ similarity, because of variation in band positions and a large number of faint bands, and were considered unreproducible. This can be explained by incomplete digestion by one of the restriction enzymes. The presence of restriction-modification systems acting on the restriction enzymes used for typing has been described for Campylobacter species (Newell et al., 2000). Because of the aberrant patterns, these C. helveticus and $C$. upsaliensis strains were not included in the numerical analysis (Fig. 1).

\section{Differentiation of Campylobacter species}

To differentiate between species, the degrees of similarity of banding patterns were calculated using the Pearson correlation coefficient and were expressed as percentage similarities. After cluster analysis by UPGMA, a dendrogram was constructed (Fig. 1). Distinct AFLP clusters were identified that were defined by banding patterns that grouped together and showed a linkage level with other clusters of less than $20 \%$. Altogether, 10 distinct AFLP clusters were observed, of which eight corresponded with the assigned taxonomic groups of these species (Fig. 1, clusters A to I). However, strains of the species C. lari were divided in two AFLP groups (Fig. 1, clusters B1 and B2). The AFLP classification of the clinical and field isolates correlated with data obtained from whole-cell protein profile analysis (data not shown). The strains of each Campylobacter species showed characteristic AFLP patterns, identified by the number and distribution of the AFLP bands (Fig. 1).

The C. jejuni subsp. jejuni cluster consisted of highly diverse AFLP fingerprints. The subspecies C. jejuni subsp. doylei showed highly homogeneous AFLP banding patterns, which were clearly differentiated from those of subsp. C. jejuni subsp. jejuni. The subspecies grouped together with a linkage level of $39 \cdot 6 \pm 4 \cdot 6 \%$ (Fig. 1, clusters F1 and F2). The AFLP banding patterns of C. coli strains contained many closely distributed bands, which were more homologous than the patterns for C. jejuni subsp. jejuni, similar to that shown previously (Fig. 1, cluster I) (Duim et al., 1999). The AFLP banding patterns of the C. lari strains were divided into two distinct clusters (Fig. 1, clusters B1 and B2). The strains in cluster B1 represented the nalidixicacid-resistant thermophilic campylobacters (NARTC), the classical biotype of C. lari. The strains of cluster B2 were nalidixic acid variants of $C$. lari, as they were all nalidixic acid sensitive (NASC). The banding patterns in the two C. lari clusters showed less than $20 \%$ similarity, which indicates that there is a difference at the DNA level for these C. lari variants.

The C. upsaliensis cluster showed banding patterns comprising a large number of bands that were highly heterogeneous (Fig. 1, cluster C). The fingerprints of $C$. upsaliensis contained a large number of bands and had to be interpreted carefully because of the unreproducibility of the pattern of one strain. The three $C$. helveticus strains also showed patterns containing many bands. These patterns were specific and grouped the strains of this species in a separate cluster after numerical analysis (Fig. 1, cluster G).

Despite the highly similar fingerprints, a differentiation between the two subspecies C. fetus subsp. fetus and C. fetus subsp. venerealis was obtained. At a high linkage level $(80 \cdot 7 \pm 1 \cdot 4 \%)$, the subspecies could be differentiated because the banding patterns consistently showed a few band differences (Fig. 1, clusters E1 and E2). For the field isolates R-4117, 5522 and 5521, the subspecies were also determined biochemically and confirmed using a subspecies-specific PCR (Hum et al., 1997; Wagenaar et al., 2001). These data correlated with the species identification obtained by AFLP analysis.

The C. hyointestinalis cluster consisted of banding patterns specific for the subsp. hyointestinalis, which were clearly separated (with a similarity level of $26 \cdot 2 \pm 5 \cdot 7 \%$ ) from banding patterns that were specific for the subsp. lawsonii (Fig. 1, groups D1 and D2).

AFLP analysis of genome fragments of C. sputorum and C. mucosalis resulted in patterns with only 11-25 bands. The bands of both species showed considerable heterogeneity, and were separately clustered (Fig. 1, groups $\mathrm{A}$ and $\mathrm{H}$ ). A differentiation between biovars of $C$. sputorum was not observed.

\section{DISCUSSION}

Several species of the genus Campylobacter are known to cause human and animal infections, and it is important for clinical and epidemiological studies that Campylobacter species are accurately differentiated. In this study, we present data showing that AFLP is a suitable genomic fingerprinting technique for the differentiation of the Campylobacter species tested. The reference strains (Table 1) showed highly distinct AFLP fingerprints between species, and when recent human and animal clinical isolates were included, the differentiation of species remained identical. Except for C. lari, strains that belonged to the same genomic species always grouped together in one particular AFLP cluster (Fig. 1).

\section{AFLP data compared with taxonomic and phylogenetic data}

The determination of total genomic DNA-DNA homology values has persisted as a dominant component of taxonomic analysis. However, recent studies have shown that AFLP genomic fingerprinting analysis is an accurate approach for determining bacterial taxonomy and for phylogenetic comparisons between bacteria (Huys et al., 1996; Janssen et al., 1997; Rademaker et al., 2000). In contrast with AFLP studies of the genera Xanthomonas, Acinetobacter and Aeromonas, the present AFLP dendrogram did not correspond with the 
phylogenetic relationships between Campylobacter species as deduced from comparative 16S rRNA genesequence analyses (Vandamme et al., 1991; Vandamme, 2000). On \& Harrington (2000) recently reported the same observation. However, all species except C. lari were separated into single clusters, and the two subspecies within C. fetus, C. hyointestinalis and C. jejuni were clearly distinguishable; this corresponded nicely with the present classification of these organisms. The results of the AFLP analysis of two strains (LMG 15882 and LMG 15884) initially described as a novel species (Campylobacter hyoilei; Alderton et al., 1995) corroborated the reported synonomy between C. hyoilei and C. coli (Vandamme et al., 1997). These data confirm the value of AFLP in studying relationships between bacteria at and below the species level.

The C. lari strains examined clustered into two distinct groups with a similarity level of $18.9 \%$. The observed differences between these groups were much larger than that obtained between the subspecies of C. jejuni, C. byointestinalis and C. fetus. The genetic diversity observed with AFLP fingerprinting confirms the reported heterogeneity among C. lari identified by using randomly amplified polymorphic DNA (RAPD) and protein analysis (Endtz et al., 1997). In a recent study, On \& Harrington (2000) used AFLP fingerprinting to demonstrate that the nalidixic-acid-resistant thermophilic and urease-positive thermophilic biovars of C. lari have substantive genetic differences. Our data identified genetic differences between nalidixic-acid-resistant thermophilic campylobacter strains and nalidixic-acidsensitive campylobacter strains, and also suggest that this nomenspecies may comprise multiple distinct genetic groups. Also, protein-profile analysis confirmed this separation of the C. lari groups. These data suggest that the different AFLP clusters within C. lari represent distinct Campylobacter taxa.

The differences observed between the AFLP patterns of C. upsaliensis indicated a considerable degree of genetic diversity between strains of this species. These data confirm the reported genotypic heterogeneity among $C$. upsaliensis strains that was observed with PFGE typing (Bourke et al., 1996). The species C. helveticus is phylogenetically the nearest neighbour of C. upsaliensis, as both species showed relative DNA homology (Stanley et al., 1992). However, the AFLP profiles of C. helveticus and C. upsaliensis were distinct and showed no homology (Fig. 1, clusters $\mathrm{C}$ and $\mathrm{H}$ ).

\section{Identification of Campylobacter species}

The AFLP clusters of all species tested were clearly distinct, and differentiation within the species C. jejuni, C. hyointestinalis and C. fetus at the subspecies level was also obtained. It can be concluded, therefore, that AFLP analysis can be used for the identification of Campylobacter strains at the species and subspecies levels. The similarity between AFLP patterns is calculated using the Pearson product-moment corre- lation coefficient applied to the complete densitometric curves of the gel tracks; this method may be more reliable than band-based calculations for comparing large numbers of patterns (Rademaker et al., 2000) and to provide a database for identification. However, for optimal species identification, it is necessary to include in the database a number of fingerprints for each species, as representations of strain relationships in dendrograms are subject to some degree of distortion and the clustering of a single pattern of a species may be incorrect.

The identification of the strains of the species C. lari may be complicated by the fact that this species belongs to distinct AFLP clusters that may represent distinct genetic groups. Of the closely related species C. jejuni and C. coli, which are the most important causes of human gastroenteritis, the identification can be problematic, because the overall phenotype and genotype of both taxa are remarkably similar. However, with AFLP analysis, the patterns show substantive differences which allow the identification of these species (Fig. 1). Also, for the species C. fetus, the currently available methods for identifying subspecies are not straightforward (Vandamme et al., 1990). Both subspecies are highly related at the genetic level, but differ in terms of hostspecificity and pathogenicity. In this study, AFLP analysis was able to separate the related subspecies from differences in only a few AFLP bands. In a larger study, it was demonstrated that AFLP analysis is able to separate field isolates of C. fetus subsp. fetus from C. fetus subsp. venerealis (Wagenaar et al., 2001). In addition, with the AFLP method described by On \& Harrington (2000), no differentiation between the subspecies was obtained.

The use of AFLP analysis as a species-identification method has the advantage that it enables species identification and shows the relationships between strains at both the taxonomic and epidemiological levels.

\section{AFLP typing of Campylobacter species}

For C. jejuni, the application of AFLP analysis to the typing of epidemiologically related and unrelated strains has been well established (Duim et al., 1999, 2000). The AFLP patterns of the two subspecies of C. hyointestinalis were well distributed and highly diverse. Recently, Harrington \& On (1999) demonstrated that extensive $16 \mathrm{~S}$ rRNA gene sequence diversity exists between the two C. hyointestinalis subspecies. The AFLP analysis confirmed the diversity between subspecies but was also able to type individual strains, as the banding patterns of individual strains showed substantial diversity. The AFLP patterns of individual strains of the species $C$. fetus were highly homologous, which supports the reported genetic homogeneity of this species, but also limits the use of AFLP typing for studying the epidemiology of this species. In contrast, the patterns for $C$. upsaliensis and C. helveticus were very diverse but this could cause problems in the interpretation of the 
patterns, as some bands were unreproducible. An additional analysis of epidemiologically related strains will be necessary in order to determine if AFLP analysis can differentiate these strains correctly and be of value for the typing of C. upsaliensis and C. helveticus. The patterns of C. sputorum and C. mucosalis showed, despite the small number of bands, sufficient diversity to permit strain typing. The differentiation of biovars of $C$. sputorum was not achieved with the small number of strains used in this study, but future analyses of larger numbers of strains may be more successful.

\section{Conclusions}

AFLP fingerprinting analysis of Campylobacter species is a reliable method that allows identification of strains at the species and subspecies levels, and it may be a suitable tool for the determination of strain relationships at the taxonomic and epidemiological levels.

\section{REFERENCES}

Alderton, M. R., Korolik, V., Coloe, P., Dewhirst, F. E. \& Paster, B. J. (1995). Campylobacter hyoilei sp. nov., associated with porcine proliferative enteritis. Int J Syst Bacteriol 45, 61-66.

Borczyk, A., Lior, H., McKeown, A. \& Svendsen, H. (1988). Isolations of Campylobacter sputorum associated with human infections. In Campylobacter IV : Proceedings of the Fourth International Workshop on Campylobacter infections, pp. 166-167. Edited by B. F. E. Kaijser. Göteborg: University of Göteborg.

Bourke, B., Sherman, P. M., Woodward, D., Lior, H. \& Chan, V. L. (1996). Pulsed-field gel electrophoresis indicates genotypic heterogeneity among C. upsaliensis strains. FEMS Microbiol Lett 143, 57-61.

Bourke, B., Chan, V. L. \& Sherman, P. (1998). Campylobacter upsaliensis: waiting in the wings. Clin Microbiol Rev 11, 440-449.

Duim, B., Wassenaar, T. M., Rigter, A. \& Wagenaar, J. A. (1999). High-resolution genotyping of Campylobacter strains isolated from poultry and humans with AFLP fingerprinting. Appl Environ Microbiol 65, 2369-2375.

Duim, B., Ang, C. W., van Belkum, A., Rigter, A., van Leeuwen, W. J., Endtz, H. P. \& Wagenaar, J. A. (2000). AFLP analysis of C. jejuni strains isolated from chickens and from patients with gastroenteritis, Guillain-Barré or Miller Fisher syndrome. Appl Environ Microbiol 66, 3197-3923.

Endtz, H. P., Vliegenthart, J. S., Vandamme, P., Weverink, H. W., van den Braak, N. P., Verbrugh, H. A. \& van Belkum, A. (1997). Genotypic diversity of Campylobacter lari isolated from mussels and oysters in The Netherlands. Int J Food Microbiol 34, 79-88.

Garcia, M. M., Eaglesome, M. D. \& Rigby, C. (1983). Campylobacters important in veterinary medicine. Vet Bull 53, 793-818.

Gebhart, C. J., Edmonds, P., Ward, H., Kurtz, H. J. \& Brenner, D. J. (1985). "Campylobacter hyointestinalis" sp. nov.: a new species of Campylobacter found in the intestines of pigs and other animals. J Clin Microbiol 21, 715-720.

Goossens, H. \& Butzler, J. P. (1992). Isolation and identification of Campylobacter spp. In C. jejuni: Current Status and Future Trends., pp. 93-109. Edited by I. Nachamkin, M. J. Blaser \& L. S. Tompkins. Washington, DC: American Society for Microbiology.

Harrington, C. S. \& On, S. L. W. (1999). Extensive $16 \mathrm{~S}$ rRNA gene sequence diversity in Campylobacter byointestinalis strains: taxonomic and applied implications. Int J Syst Bacteriol 49, 1171-1175.

Hum, S., Quinn, K., Brunner, J. \& On, S. L. W. (1997). Evaluation of a PCR assay for identification and differentiation of Campylobacter fetus subspecies. Aust Vet J 75, 827-831.

Huys, G., Coopman, R., Janssen, P. \& Kersters, K. (1996). Highresolution genotypic analysis of the genus Aeromonas by AFLP fingerprinting. Int J Syst Bacteriol 46, 572-580.

Jacobs-Reitsma, W., Bolder, N. M. \& Mulder, R. W. A. W. (1994). Caecal carriage of Campylobacter and Salmonella in Dutch broiler flocks at slaughter: a one-year study. Poultry Sci 73, 1260-1266.

Janssen, P., Maquelin, K., Coopman, R., Tjernberg, R., Bouvet, P., Kersters, K. \& Dijkshoorn, L. (1997). Discrimination of Acinetobacter genomic species by AFLP fingerprinting. Int J Syst Bacteriol 47, 1179-1187.

Kokotovic, B. \& On, S. L. W. (1999). High-resolution genomic fingerprinting of Campylobacter jejuni and Campylobacter coli by analysis of amplified fragment length polymorphisms. FEMS Microbiol Lett 173, 77-84.

Lastovica, A. J. \& Skirrow, M. B. (2000). Clinical significance of Campylobacter and related species other than Campylobacter jejuni and C. coli. In Campylobacter, 2nd edn, pp. 89-120. Edited by I. Nachamkin \& M. J. Blaser. Washington, DC: American Society for Microbiology.

Lawson, A. J., On, S. L., Logan, J. M. \& Stanley, J. (2001). Campylobacter hominis sp. nov., from the human gastrointestinal tract. Int J Syst Evol Microbiol 51, 651-660.

Logan, J. M., Burnens, A., Linton, D., Lawson, A. J. \& Stanley, J. (2000). Campylobacter lanienae sp. nov., a new species isolated from workers in an abattoir. Int J Syst Evol Microbiol 50, 865-872.

Newell, D. G. \& 6 other authors (2000). New developments in the subtyping of Campylobacter strains. In Campylobacter, 2nd edn. Edited by I. Nachamkin \& M. J. Blaser. Washington, DC: American Society for Microbiology.

On, S. L. W. (1996). Identification methods for campylobacters, helicobacters, and related organisms. Clin Microbiol Rev 9, 405-422.

On, S. L. \& Harrington, C. S. (2000). Identification of taxonomic and epidemiological relationships among Campylobacter species by numerical analysis of AFLP profiles. FEMS Microbiol Lett 193, 161-169.

On, S. L. W., Bloch, B., Holmes, B., Hoste, B. \& Vandamme, P. (1995). Campylobacter hyointestinalis subsp. lawsonii subsp. nov., isolated from porcine stomach, and an emended description of Campylobacter hyointestinalis. Int J Syst Bacteriol 45, 767-774.

Rademaker, J. L. W., Hoste, B., Louws, F. J., Kersters, K., Swings, J., Vauterin, L., Vauterin, P. \& de Bruijn, F. J. (2000). Comparison of AFLP and rep-PCR genomic fingerprinting with DNA-DNA homology studies: Xanthomonas as a model system. Int J Syst Evol Microbiol 50, 665-677.

Savelkoul, P. H., Aarts, H. J., de Haas, J., Dijkshoorn, L., Duim, B., Otsen, M., Rademaker, J. L., Schouls, L. \& Lenstra, J. A. (1999). Amplified-fragment length polymorphism analysis: the state of an art. J Clin Microbiol 37, 3083-3091.

Skirrow, M. B. \& Blaser, M. J. (1992). Clinical and epidemiologic considerations. In Campylobacter jejuni: Current Status and Future Trends, pp. 3-9. Edited by I. Nachamkin, L. S. Tompkins \& M. J. Blaser. Washington, DC: American Society for Microbiology.

Stanley, J., Burnens, A. P., Linton, D., On, S. L. W., Costas, M. \& 
Owen, R. J. (1992). Campylobacter helveticus sp. nov., a new thermophilic species from domestic animals: characterization, and cloning of a species-specific DNA probe. J Gen Microbiol 138, 2293-2303.

Vandamme, P. (2000). Taxonomy of the family Campylobacteriaceae. In Campylobacter, 2nd edn, pp. 3-26. Edited by I. Nachamkin \& M. J. Blaser. Washington, DC: American Society for Microbiology.

Vandamme, P., Pot, B., Falsen, E., Kersters, K. \& De Ley, J. (1990). Intra- and interspecific relationships of veterinary campylobacters revealed by numerical analysis of electrophoretic protein profiles and DNA: DNA hybridizations. Syst Appl Microbiol 13, 295-303.

Vandamme, P., Falsen, E., Rossau, R., Hoste, B., Segers, P., Tytgat, R. \& De Ley, J. (1991). Revision of Campylobacter, Helicobacter and Wolinella taxonomy: emendation of generic descriptions and proposal of Arcobacter gen. nov. Int J Syst Bacteriol 41, 88-103.
Vandamme, P., van Doorn, L.-J., Rashid, S. T. A., Quint, W. G. V., Plas, J. v. d., Chan, V. L. \& On, S. L. W. (1997). Campylobacter byoilei Alderton et al. 1995 and Campylobacter coli Veron and Chatelain 1973 are subjective synonyms. Int J Syst Bacteriol 47, 1055-1060.

Vauterin, L. \& Vauterin, P. (1992). Computer-aided objective comparsion of electrophoresis patterns for grouping and identification of microorganisms. Eur Microbiol 1, 37-41.

Wagenaar, J. A., van Bergen, M. A. P., Newell, D. G., GrogonoThomas, R. \& Duim, B. (2001). Comparative study using amplified fragment length polymorphism fingerprinting, PCR genotyping, and phenotyping to differentiate Campylobacter fetus strains isolated from animals. J Clin Microbiol 39, 2283-2286.

Received 26 February 2001; revised 12 June 2001; accepted 19 June 2001. 